\title{
REVIEW OF LONG-TERM WARRANTY POLICIES
}

\author{
Anisur Rahman* and Gopinath Chattopadhyay ${ }^{* *}$ \\ Queensland University of Technology, School of \\ Engineering System, 2 George Street, P.O Box 2434 \\ Brisbane QLD 4001, AUSTRALIA \\ a2.rahman@qut.edu.au \\ g.chattopadhyay@qut.edu.au
}

\begin{abstract}
A large number of products are now being sold with long-term warranty policies. This is mainly due to fierce competition in the market and customer demand. Offering long term warranty results in additional complexities in estimating costs associated with warranty servicing due to the uncertainties associated with usage, preventive maintenance and warranty servicing strategies. This paper reviews various long-term warranty policies and mathematical models for estimation of warranty servicing costs.
\end{abstract}

Key words: Long-term Warranty Policies, Warranty cost models

\section{Introduction}

Reliability of product has been becoming increasingly important due to market competition, high servicing costs associated with ever increasing new technologies and customer/buyer demand for longer warranty period. This is assured by offering after sales service to the customer/buyer. Currently, a large number of products are being sold with long-term warranty policies. These policies come in the form of extended warranty, warranty for used products, service contracts and lifetime warranty policies. Estimation of costs for these warranties is complex because it is often difficult to define performance measures of products for different applications. In addition there are uncertainties associated with usage, preventive maintenance and warranty servicing strategies.

This paper provides an overview of literature on long-term warranty policies. The outline of the paper is as follows. Section 2 provides the role and concepts of warranty policies. Section 3 reviews literature on long-term warranty policies and cost models for industry application. In section 4, the contribution of this paper and scope for future work are discussed.

\section{Background: Role and Concept of Warranty}

A warranty offered by a manufacturer or dealer is a contractual obligation in connection with the sale of a product (Murthy and Blischke, 1992a). The warranty specifies that the manufacturer/dealer agrees to rectify certain defects or failures in the product for specified period of time after the sale of the product. Various types of warranty policies have been developed and studied from both manufacturer and 
buyer's perspectives. These studies deal with various issues ranging from technical (warranty and product design or manufacturing) to commercial (warranty and marketing, warranty servicing) and the effective management of the warranty process. An elaborate list of warranty studies can be found in Murthy and Djamaludin (2002). Djamaludin et al, (1996) reviewed a list of over 1500 papers on warranties. For warranty cost models, see Blischke and Murthy (1994). For other issues related to warranties see Blischke and Murthy (1996).

\subsection{Role of warranty}

Role of warranty is different to the customer/user, the manufacturer/dealer, underwriting insurer (if any) and to the public policy makers:

- To the manufacturer: it plays protective role by limiting its liability in case of failure due to improper and careless use or abuse of product by the customer. It also plays the promotional role by signalling the quality of products to the consumers and finally, it acts as a powerful advertising tool for a manufacturer/ dealer to compete effectively in the market.

- To the customer: it plays both protective role (by providing insurance against early failures of an item due to design, manufacturing or quality assurance problem/s during the warranty period) and informative role (by acting as indicators of the quality and reliability of the product in the context of complex and/or innovative products where the customer is unable to evaluate product performance due to lack of knowledge, expertise or experience).

- To the public policy maker: it plays statutory role to enact laws to see that warranty terms are fair and there are mechanisms to resolve conflicts arising from warranty claims.

\subsection{Warranty taxonomy}

Blischke and Murthy (1992) proposed a taxonomy for warranty policies for new products and grouped these policies into three categories such as, Type A (single item sale and not involving product development and also can be divided into one and two-dimensional policies), Type B (group of items and not involving product development), and Type C (involving product development).

Murthy and Chattopadhyay (1999) developed policies and taxonomy for second hand products. Warranty policies were classified under three groups namely, Group A (Non-renewing policies), Group B (Renewing policies), and Group C (buy-back policies - under these policies the dealers are bound to return the money to the buyer, if the product fails any time during the warranty period).

\subsection{Warranty cost}

The additional cost due to warranty servicing is important to the manufacturer as it directly influences the selling price and profit. From the manufacturer's point of view a warranty offer is worthwhile if the profit margin, considering total cost including the additional cost due to warranty servicing, is improved through an increase in sales and/or reduction in warranty servicing costs.

Following costs are generally modelled and analysed for warranty policy decisions.

- Warranty costs per unit sale: whenever a warranty claim occurs, it incurs additional costs to the manufacturer/dealer. Warranty servicing cost is a random variable since claims under warranty and rectification of each claim are uncertain. Warranty cost per unit sale can be estimated from the total cost of warranty and the 
number of units sold. The total cost includes repair or replacement costs, and/ or downtime cost, and/or the product improvement cost along with administrative costs (For details see Blischke and Murthy 1994).

- Life cycle costs (LCC): this cost is important to both buyer and manufacturer for complex and expensive products and is dependent on the life cycle of the product. Life cycle starts with the launch of a product onto the market and ends when the manufacturer stops producing the product or when it is withdrawn from the market due to the launch of a new product. This cost over the product life cycle is a random variable. (For details see Blischke and Murthy 1994)

\subsection{Warranty cost analysis}

Predicting failure, modelling warranty cost and analysis for one dimensional (due to one variable such as time, usage or number of time the product is used) warranty policies have received a lot of attention in the literature. Modelling of warranty cost analysis from an engineering point of view has been covered in Blischke and Murthy (1992). Menke (1962) and Lawerre (1968) developed the earliest probabilistic models for warranty cost for rebate policy. They considered a free replacement policy. Menke assumes an exponential failure distribution for a product. Amato and Anderson (1977) extends Menke's model to allow for discounting and price adjustment to estimate the warranty cost for products with general failure time distribution. Karmarkar (1978) and Balachandran et al. (1981) proposed models for failure free fixed period warranty policies. Heschel (1971) and Thomas (1981) studied the expected costs and profit per unit time for an infinite life cycle for combination warranty policies. They did not consider the effect of replacement over the product life cycle. Blischke and Scheur (1975) modelled the costs over the product life cycle. They estimated the failure distribution function from incomplete data using the Kaplan and Meier (1958) technique to analyse FRW (free replacement warranty) and PRW (pro-rated replacement warranty) policies. They looked into the problem from the manufacturer and consumer point of view by comparing the product lifecycle costs and the profits for items sold with and without warranty.

Blischke and Murthy (1994), analysed warranty costs from manufacturer's and consumer's point of view for various distribution functions such as exponential, Weibull, gamma, lognormal and mixed exponential. The steps in the warranty cost analysis involve the modelling of failures and the cost of rectification actions over the warranty period. Failures over the warranty period can be modelled either at component level or at product (or item) level. At component level, failure of each component can be modelled separately and the modelling of first failure needs to be treated different from that of subsequent failures. It depends on type of the component (repairable/non-repairable) and also on the type of rectification actions (minor repair, major repair or overhauling or replacement with a new or used one). Time to failure for the first failure is modelled using the probability distribution function whereas subsequent failure are modelled based on the repair actions (ordinary renewal process if the product is non-repairable and replaced by new or delayed renewal process for replaced by clone). Preliminaries of the stochastic point processes and their role in modelling item failure and cost for warranty study is briefly described as follows.

\section{Ordinary renewal process:}

In this case, replacements are considered for non-repairable component and the expected number of renewal in $[0, w), M(w)$ can be obtained from 


$$
M(w)=F(w)+\int_{0}^{W} M(w-x) f(x) d x
$$

Where, $w$ represents warranty period, and $F(w)$ and $f(x)$ represent cumulative failures distribution and probability density function respectively.

The total warranty cost at any time $x, 0 \leq x \leq w$, is given by

$$
C(w)=c_{f}\left[F(w)+\int_{0}^{w} M(w-x) f(x) d x\right]
$$

Where $c_{f}$ is the cost of a new item.

\section{Delayed renewal or point process}

Failed components are repaired imperfectly or replaced by a clone or used one. Failure distribution of repaired component is $G(x)$, which is different from the failure distribution of first failure $F(x)$. Let $M_{d}(t)$ denote the expected number of renewals over $[0, w)$ and is given by

$$
M_{d}(t)=F(w)+\int_{0}^{w} M_{g}(w-x) f(x) d x
$$

and the expected warranty cost is given by

$$
C_{j}=c_{j}\left[F(w)+\int_{0}^{w} M_{g}(w-x) f(x) d x\right]
$$

where, $M_{g}($.$) is the renewal function associated with the failure distribution function$ $G($.$) for repaired items [for details see Ross (1970)]. C_{j}$ and $c_{j}$ are the total expected warranty cost and the mean value of each repair cost respectively.

\section{Non-homogeneous Poisson Process}

Failures of the system (product) can be viewed as a point process and the failures can be modelled by a non-stationary Poisson process with an intensity function $\Lambda(t)$ which is increasing function with time $t . F(t)$ denotes the cumulative failure distribution and if modelled as Weibull distribution is given by:

$$
F(t)=1-\exp \left(-(\lambda t)^{\beta}\right)
$$

$\Lambda(t)$ is given by:

$$
\Lambda(t)=\frac{f(t)}{1-F(t)}=\frac{\lambda \beta(\lambda t)^{\beta-1} \exp \left(-(\lambda t)^{\beta}\right)}{1-\left(1-\exp \left(-(\lambda t)^{\beta}\right)\right.}=\lambda \beta(\lambda t)^{\beta-1}
$$

with $\beta>1$ and $\lambda>0$. where $\beta$ and $\lambda$ are Weibull parameters. Expected number of failure $\mathrm{E}[N(w)]$ within warranty period $w$ is given by

$$
E[N(w)]=\int_{0}^{w} \Lambda(t) d t
$$

Expected warranty cost to the manufacturer for unit sale, $E\left[C_{m}().\right]$ as modelled by Blischke and Murthy (2000) is given by

$$
E\left[C_{m}(w)\right]=C_{s}[1+E[N(w)]]
$$

where, $C_{s}$ is the total manufacturing cost per unit.

\subsection{Warranty servicing mechanisms}

The additional cost due to warranty depends on servicing strategies (minimal repair, major repair, overhauling, and replacement with new one or used one) during the warranty period.

Replace vs repair: the manufacturer/dealer has the option for repairing or replacing a failed item with a new or good condition used item or refund a part or full purchase price. Repair cost is estimated and compared with replacement cost and the decision is taken based on whichever is less. Murthy and Nguyen (1985a) modelled a two 
component product with failure interaction where failure of one component induces the failure of the other component. Murthy and Nguyen (1985b) extended this model for system with n-components. Reliability improvement through overhaul or imperfect maintenance has received some attention in the literature. Jack and Dagpunar (1994) studied the optimal imperfect maintenance over the warranty period. Dagpunar and Jack (1994) developed a preventive maintenance strategy over the warranty period. Murthy and Jack et al. (2003) studied and analysed the warranty servicing cost of repairing failed item and suggested that can be minimised through optimal corrective maintenance decision. Chukova et al. (2004) developed model to analyse warranty cost when imperfect repair is undertaken. Iskander et al. (2005) proposed a new repair replacement strategy for products sold with two dimensional warranties.

Murthy and Nguyen (1988) proposed a model in which the failed item is first inspected to assess the rectification cost. If this cost exceeds a certain limit, a replacement is suggested; otherwise the repair is carried out at no cost to the buyers.

\section{Long-term Warranty Policies}

Manufactures in recent years have started to extend the coverage period of warranty policies. As a result, in recent years, the manufacturers have started offering long-term warranty policies for their products. Rahman and Chattopadhyay (2004) developed a framework for long-term warranty policies (see figure 1).

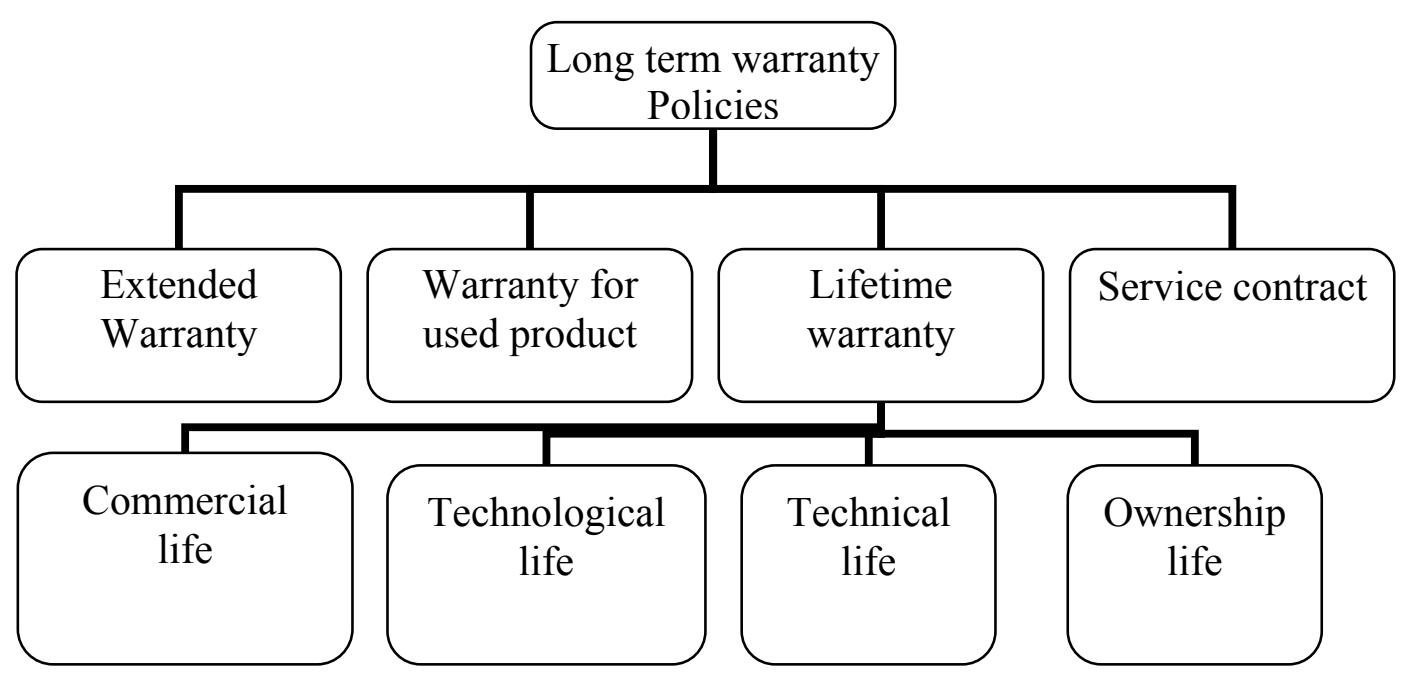

Figure 1: A framework for long-term warranty (Rahman and Chattopadhyay, 2004)

\subsection{Extended Warranty}

An extended warranty is the extension of the base warranty which is an obligation or responsibility assumed by the manufacturer or dealer for further service to buyers beyond base warranty period for a certain premium. The base warranty is an integral part of a product sale and it's cost is factored into the sales price (Murthy and Jack 2003). Consumers who prefer extra protection purchase additional coverage in the form of extended warranty or the extended service contract. It has been observed that 
on an average $27 \%$ of the new car buyers purchase extended warranty (Kumar and Chattopdhyay, 2004). Extended warranty generates significant amount of revenue to manufacturers. Sears Roebuck reported a revenue generation of nearly US\$ 1 billion from the sale of extended warranties. The annual sale of extended warranties in UK alone is more than US\$1 billion. These are sold by the manufacturer, dealers or by third parties. An independent insurer/ under-writer can change the manufacturer's warranty and pricing policies which can have an impact on manufacturers' profit and consumer's purchasing intention (Padmanabhan et al., 1993).

Extended warranty has attracted significant attention among practitioners. However, the academic research on extended warranty is limited. Padmanabhan (1995) analysed the impact of usage heterogeneity and extended service contract. He modelled the buyers and manufacturers preference attitudes to risk using utility function. He argues that variations in consumers' demands depend on their usage habit. The heavy users of the product prefer extended warranty more compared to the light users. So it would be less risky for the service providers to exclude the heavy users if the number of the heavy user is small compared to the number of light users. Lutz and Padmanabhan (1998) analysed the effect of extended warranties on a manufacturer's warranty policy under conditions of manufacturer's moral hazard. They proposed that the consumer's income influences the demand for the extended warranty. The high income earners prefer to buy this type of warranty as they have lower marginal utility for wealth. They stated the effect of competition from extended warranties in a market made up of consumers who differ in the value they receive from a working unit. They advocated that, because of two types of consumers (such as low and high valuation in the market), the manufacturer can attempt to sell a different version of the products. It results in offering a product at price $p^{L}$ with warranty $w^{L}$, and quality $q^{L}$ to low valuation consumers, and price $p^{H}$, with warranty $w^{H}$ and quality $q^{H}$ to high valuation consumers. Since the manufacturer cannot identify any individual consumer's type, he will have to choose a menu of contracts $\left(p^{L}, w^{L}\right)$ and $\left(p^{H}, w^{H}\right)$ to satisfy constraints imposed by the consumers' behaviour that maximizes utility. The manufacturer's maximised profit can then be given by

$$
P_{\max }=\lambda\left(p^{L}-\left(1-q^{L}\right) w^{L}-c\left(q^{L}\right)\right)+(1-\lambda)\left(p^{H}-\left(1-q^{H}\right) w^{H}-c\left(q^{H}\right)\right)
$$

Subject to the constraints

$$
E\left(L, q^{L}, p^{L}, w^{L}\right) \geq \max \left\{0, E\left(L, p^{H}, q^{H}, w^{H}\right)\right\}
$$

and

$$
E\left(H, q^{H}, p^{H}, w^{H}\right) \geq \max \left\{0, E\left(H, p^{L}, q^{L}, w^{L}\right)\right\}
$$

Where, $\mathrm{c}\left(\mathrm{q}^{\mathrm{L}}\right)$ and $\mathrm{c}\left(\mathrm{q}^{\mathrm{H}}\right)$ are the manufacturer's cost of producing a unit with qualities $L$ and $H$ category respectively and $\lambda \epsilon[0,1]$ is the fraction of consumer in the market.

Hollis (1999) carried out an economic study of the extended warranty market with a focus on duration of extended warranty. Mitra and Patanakar (1997) proposed a cost model where the product is sold with a rebate policy and the buyer has the option to extend the warranty till the product failure has not occurred during the initial warranty period.

They proposed following two warranty policies:

1) An initial warranty period is $w_{1}$, an additional warranty is offered up to time $w$ (from the date of sale) on items that did not fail during the initial warranty period. The rebate function is given by:

$$
r(t)=\left\{\begin{array}{cc}
c & 0 \leq t<w_{1} \\
c^{*} & w_{1} \leq t<w
\end{array}\right.
$$


Where, $c$ and $c^{*}$ are the price of the product and amount of lump-sum rebate offered during the second period. and

2) Lump-sum rebate for the initial warranty is $c$, the price of the product and for the renewable part, the rebate is pro-rated starting from a value $\mathrm{c}^{*}$, which is less than $c$ and reduces to zero at time $w$. The rebate function is given by

$$
r_{2}(t)=\left\{\begin{array}{cc}
c, & 0 \leq t \leq w_{1} \\
c^{*}\left(1-\frac{t-w_{1}}{w-w_{1}}\right), & w_{1} \leq t \leq w
\end{array}\right.
$$

Rinsaka and Sandoh (2001) studied the extension of the contract period. Yeh and Peggo (2001) developed extended warranty policies and analysed from consumers and manufacturers perspective. They proposed optimal cost models for extended warranty by considering two cost criteria namely; total expected discounted cost and long-run average cost per unit time.

These costs are given respectively by

The total expected discounted cost to a consumer

$$
T_{c n}(k)=\left\{c_{R}+\frac{c_{N} e^{(-\delta W)}\left(1-e^{(-k L)}\right)}{1-e^{-(\delta L)}}\right\} \frac{1}{1-e^{(-\delta(W+k L))}}
$$

And the total expected discounted manufacturer's cost

$$
T_{m n}\left(c_{p} c_{N} k\right)=\frac{c_{r}+c_{m}(W+k L)}{1-e^{-\delta(W+k l)}}-\frac{c_{R}\left(1-e^{(\delta L)}\right)+c_{N}\left(e^{(-\delta W)}\right)\left(1-e^{-\delta k L}\right)}{\left(1-e^{(-\delta L)}\right)\left(1-e^{-\delta(W+k L)}\right)}
$$

Where, $c_{R}, c_{N}, c_{p} c_{m}$, and $c_{r}$ are the cost of initial purchase price, renewal cost to the consumer, repair cost, manufacturing cost and manufacturer's repair cost of each rectification respectively. $W$ and $L$ are the normal and extended warranty period, $k($ $=1,2, .$.$) is the number of renewal or repair up to L . \delta$ represents the discount rate over time.

Average long run cost for consumer $A_{c n}(k)$, and manufacturer $A_{m n}\left(c_{p}, c_{N}, k\right)$, for $k$ renewals are given by

$$
A_{c n}(k)=\frac{c_{R}+k c_{N}}{W+k L}
$$

And

$$
A_{m n}\left(c_{p}, c_{N}, k\right)=\frac{c_{p}(M(W+k L))-\left(c_{R}-c_{r}\right)-k c_{N}}{W+k L}
$$

Where, $M(W+k L)$ is the renewal function over the period $W+k L$ and $c_{p}$ is the repair cost when warranty is not renewed. Yeh and Peggo (2001) found a critical point at which consumer is indifferent to the policies and derived optimal extended warranty policy for the manufacturer around that point. Kumar and Chattopadhyay (2004) developed mathematical models to estimate the minimum duration of extended warranty that would benefit the customers opting for extended warranty. They modelled the associated costs for manufacturer for providing extended warranty. Under minimal repair strategy, the cumulative hazard function, $H(t)$, is given by

$$
H(t)=\int_{0}^{t} h(x) d x
$$

For Weibull distribution, it is given by $H(t)=\left(\frac{t}{\eta}\right)^{\beta}$ 
Assume that a product is sold under initial warranty (standard warranty) of ' $\mathrm{T}$ ' life units. Minimum duration of extended warranty, $t_{e w}$, a customer should purchase under the minimal repair policy was given by

$$
t_{\text {ew }}=\left(T^{\beta}+\eta^{\beta}\right)^{1 / \beta}-T
$$

where $\eta$ is the scale parameter and $\beta$ is the shape parameter of the Weibull distribution.

A customer needs to make a decision whether to buy an extended warranty and a manufacturer needs to decide the price of offering it to their customer. The expected total cost to manufacturer for extended warranty is given by:

$$
C_{F R W}\left(T+t_{e w}\right)=C_{S}\left[1+M\left(T+t_{e w}\right)\right]
$$

Where $C_{s}$ is the cost of the product and $M(t)$ is the renewal function for the expected number of failures and is given by:

$$
M\left(T+t_{e w}\right)=F\left(T+t_{e w}\right)+\int_{0}^{T+t_{e w}} M\left(T+t_{e w}-x\right) d F(x)
$$

$F(t)$ is the cumulative failure distribution function. The cost of providing extended warranty, $C_{e w}\left(t_{e w}\right)$, for $t_{e w}$ is given by:

$$
C_{e w}\left(t_{e w}\right)=C_{s}\left[M\left(T+t_{e w}\right)-M(T)\right]
$$

For third party (underwriting insurer) under minimal repair, the cost of providing extended warranty for $t_{e w}$ is given by:

$$
C_{e w}\left(t_{e w}\right)=C_{r}\left[H\left(T+t_{e w}\right)-H(T)\right]
$$

where $C_{r}$ is the mean repair cost. For Weibull distribution the cost can be given by:

$C_{e w}\left(t_{e w}\right)=\frac{C_{r}}{\eta^{\beta}}\left(\left(T+t_{e w}\right)^{\beta}-T^{\beta}\right)$

\subsection{Warranty for used product}

Warranty for used product is offered with sale of second hand products when sold by the dealer [for details see Chattopadhyay and Murthy $(2000 ; 2001 ; 2004)$ ]. The market for second hand products as a fraction of the total market (new + second-hand) has been continuously increasing as new products are appearing at a faster rate in the market and the expected life of products is increasing due to rapid advances in technology. In the US car market, the trade for second hand cars was $40 \%$ of that for new cars in numbers and $22 \%$ in terms of dollar sales (Genesove, 1993). Buyers are demanding warranties for items purchased from the dealers of second-hand or used products. In response to consumer demand, public policy makers have begun enacting laws requiring dealers to offer warranties for second-hand products and service warranty claims. Dealers of used products have now started using warranty to promote sales.

Decisions related to second-hand products are more complex compared to new products due to the fact that each second-hand product is statistically different from other similar products due to variation of age, usage and previous maintenance history. Therefore, dealers of second-hand products need to formulate policies and conduct a proper cost analysis of warranty policies applicable to second-hand products. This is necessary to avoid making loss instead of profit. Chattopadhyay and 
Murthy (1996) is the earliest paper to develop a cost model of a warranty policy for second-hand products.

Davis (1952) provides an opportunity to improve the reliability of used items through reconditioning/ overhaul. He modelled reliability of reconditioned bus engines actions to analyse effect on failure rate. Reconditioning/ overhaul allow dealers to offer better warranty terms and sell an item at a higher price. However, reconditioning/ overhaul is worthwhile if the expected saving in the warranty servicing cost or the increased profit due to increased sale price exceeds the costs associated with the improvement. Bhat (1969) introduced the application of used-item in rectification. Nakagawa (1979) developed optimum replacement policies for used units. Malik (1979) introduced a "degree of improvement" in the failure rate and called it the "improvement factor". Kijima et al (1988) and Kijima (1989) modelled virtual age where the improvement results in a reduction in the age of the system from.

Wogalter et al. (1998) studied the availability of operator manuals for used (secondhand or resold) consumer products (e.g. car, computer, lawnmower, bicycle, etc.).

Chattopadhyay and Murthy (2000) proposed stochastic models to estimate the expected warranty cost for second-hand products. They discussed two approaches:

Approach 1: the system is viewed as a black-box and the claims are modelled as point process with an intensity function $\Lambda(t)$ where $t$ represents the age of the system. The function $\Lambda(t)$ is an in-creasing function of $t$ indicating that the number of claims (in a statistical sense) increases with age. This type of characterisation is appropriate when system failures occur due to a component failures and the system can be made operational through repair or replacement of the failed component using minimal repair strategy.

For this approach the expected warranty cost (with free replacement warranty) is given by $C(W ; A)$ when the item is of age, $\mathrm{A}$, at sale. $A$ is a random variable assuming values in the range of age $[L, U]$ and characterised by a distribution function $H(a)$, with $H(L)=0$ and $H(U)=1 . h(a)$ denotes the density function associated with $H(a)$.

$$
C(w)=E[C(w ; A)]=C_{r} \int_{L}^{U}\left\{\int_{A}^{A+w} \Lambda(t) d t\right\} h(a) d a .
$$

$C_{r}$ denotes the expected cost of each rectification action. Using $C(w)$ instead of $C(w$; A) in the pricing decision implies that the dealer is charging the same amount for warranty for items within defined age range. They provided a linear refund function for the pro-rata warranty (PRW) policy. The item fails after a period $x$ subsequent to the sale. Then, the refund function, $R(x)$, is given by

$$
R(x)=\left\{\begin{array}{ccc}
C_{s}\left[1-\frac{x}{w}\right] & \text { for } & 0 \leq x \leq w \\
0 & \text { for } & x>w
\end{array}\right\}
$$

And the expected warranty cost for PRW policy is given by

$$
C(w)=\int_{0}^{W} R(x) d F(x)=C_{s}\left(F(w)-\frac{1}{w} \int_{0}^{W} x d F(x)\right)
$$

where, $C_{s}$ denotes the sale price.

Approach 2: the claims were characterised through failures at component level. The total expected warranty cost for the system is given by the sum of the costs for the different components where the component failures are independent.

First failure: If the age $A_{i}$ of the component is known and is given by $A_{i}=a_{i}$, then the time to first failure, $X_{i l}$, is given by the distribution function $F_{i l}(x)$. It is given by 


$$
F_{i 1}(x)=\frac{F_{i}\left(a_{i}+x\right)-F\left(a_{i}\right)}{1-F_{i}\left(a_{i}\right)}
$$

The expected number of failures over the warranty period is modeled as a modified renewal process with first failure given by $F_{i 1}(x)$ and subsequent failures by $F_{i}(x)$.

Then the expected warranty cost, $C_{i}\left(w ; a_{i}\right)$, is given by:

$$
C_{i}\left(w_{i} ; a_{i}\right)=c_{i}\left[F_{i 1}(w)+\int_{0}^{W} M_{i}(w-x) d F_{i 1}(x)\right]
$$

where $M_{i}$ (.) is the renewal function associated with $F_{i}(),. c_{i}$ is the cost of each failure rectification. Chattopadhyay and Murthy (2001) developed and analysed stochastic models for three new cost sharing warranty policies for second-hand products.

Specific parts exclusion [SPE]:- The components of the product are grouped into two disjoint sets, I (for inclusion) and E (for exclusion). Under this policy, the dealer rectifies failed components belonging to set I at no cost to the buyer over the warranty period. The costs of rectifying failed components belonging to set $\mathrm{E}$ are borne by the buyer. They modelled the failures during warranty using two different approaches.

Approach 1: Here the failures were modelled by a point process with common intensity function $\Lambda(t)$. At each point (corresponding to a failure) they used mark which indicated whether the item failure was covered under warranty or not and this mark was modelled as a binary random variable $Y$ with $Y=1$ indicated that the failure was covered and 0 indicated that the failure was not covered under warranty.

The expected number of failures for an item of age A at sale covered under warranty for a period $\mathrm{W}$ was given by

$$
E\left[N_{I}(w ; A)\right]=(1-p) \int_{A}^{A+w} \Lambda(t) d t
$$

Similarly, the expected number of failures not covered under warranty was given by

$$
E\left[N_{E}(w ; A)\right]=p \int_{A}^{A+w} \Lambda(t) d t
$$

where, $P\{Y=0\}=p$ and $P\{Y=1\}=1-p$

Approach 2:

Here component failures belonging to set $I$ were modelled by an intensity function $\Lambda_{I}(t)$ and for those belonging to set $E$ were modelled by another intensity function $\Lambda_{E}(t)$. Both of these were increasing functions of time $t$. Then $N_{I}(W ; A)$ and $N_{E}(W ; A)$ were distributed according to non-stationary Poisson process with intensity functions $\Lambda_{\mathrm{I}}(\mathrm{t})$ and $\Lambda_{\mathrm{E}}(\mathrm{t})$ respectively and their expected values are given by:

$$
E\left[N_{I}(w ; A)\right]=\int_{A}^{A+w} \Lambda_{I}(t) d t
$$

and

$$
E\left[N_{E}(w ; A)\right]=\int_{A}^{A+w} \Lambda_{E}(t) d t
$$

The cost of each rectification resulting from failures due to components belonging to set $E$ and set $I$ were modelled by distribution functions $G_{E}(c)$ and $G_{I}(c)$ with mean $\bar{c}_{E}$ and $\bar{c}_{I}$ respectively. Expressions for the mean values are given by $\bar{c}=\int_{0}^{\infty} c g(c) d c$ using the appropriate distribution function. $\mathrm{g}(\mathrm{c})$, the density function derived from distribution function $\mathrm{G}(\mathrm{c})$. 
Limit on individual cost [LIC]:- if the cost of a rectification is below a limit $c_{i}$, it is borne completely by the dealer whereas if the cost of a rectification exceeds $c_{i}$, then the buyer pays the rest.

Here, the total expected warranty cost to the dealer, $\mathrm{E}\left[\mathrm{C}_{\mathrm{d}}(\mathrm{w} ; \mathrm{A})\right]$, is given by

$$
E\left[C_{d}(w ; A)\right]=\bar{c}_{d} \int_{A}^{A+w} \Lambda(t) d t
$$

and the total expected cost to the buyer, $\mathrm{E}\left[\mathrm{C}_{\mathrm{b}}(\mathrm{w} ; \mathrm{A})\right]$, is given by

$$
E\left[C_{b}(w ; A)\right]=\bar{c}_{b} \int_{A}^{A+w} \Lambda(t) d t
$$

Where, the expected cost of each rectification to the dealer is given by

$$
\bar{c}_{d}=\int_{0}^{c_{I}} \operatorname{cg}(c) d c+c_{I} \bar{G}\left(c_{I}\right)
$$

and that to the buyer is given by

$$
\bar{c}_{b}=\int_{c_{I}}^{\infty}\left(c-c_{I}\right) g(c) d c
$$

Limit on individual and total cost [LITC]: - the cost to the dealer has an upper limit $\left(c_{T}\right)$ for each rectification and the warranty ceases when the total cost to the dealer (subsequent to the sale) exceeds $c_{T}$ or at time $W$, whichever occurs first. The buyer pays the difference between rectification cost and the dealer's cost.

Then expected total cost to the dealer is given by

$$
E\left[C_{d}(w ; A)\right]=\int_{0}^{c_{T}} z v_{d}(z) d z+c_{T} \bar{V}_{d}\left(c_{T}\right)
$$

where, $v_{d}(z ; t)$ is the density function associated with $V_{d}(z ; t)$ (the distribution function for the total cost to the dealer by time $t$ and is given by

$$
\left.V_{d}(z ; t)=\sum_{r=0}^{\infty} G_{d}^{r}(z)[\operatorname{Pr} o b\{N(t)=r\}]\right)
$$

where, $G_{d}^{r}(z)$ is the $r$ fold convolution of distribution function of dealers cost of rectifications using $G_{d}(z)$. The expected cost to the buyer until warranty expires when $Z_{t}$ (total cost to the dealer by time t) first time crosses $c_{T}$ and is given by

$$
E\left[C_{b}(w ; A)\right]=E\left[N\left(t_{b}\right)\right] \int_{c_{I}}^{\infty}\left(c-c_{I}\right) g(c) d c
$$

and expected number of failures over $\left[0, T_{b}\right)$ is given by

$$
E\left[N\left(t_{b}\right)\right]=\int_{0}^{w}\left[\int_{A}^{A+t} \Lambda(x) d x\right] q\left(t ; c_{T}\right) d t
$$

where $q\left(t ; c_{T}\right)$ is the density function of $T_{b}$

The authors suggested simulation approach because the model is analytically complex.

Chattopadhyay and Murthy (2004) proposed optimal decision models on reliability improvement through upgrading actions by dealers before sale of second-hand products sold with warranty. They considered two problems.

Problem 1: Here the sale price and warranty terms are specified and do not depend on the reliability improvement. The upgrade (improvement) is used to reduce the expected warranty servicing cost.

For this instance, the expected profit is given by

$$
J(w, \tau ; A)=S(w ; A)-c \tau^{\psi} A^{\xi}-\bar{c} \lambda^{\beta}\left\{(A+w-\tau)^{\beta}-(A-\tau)^{\beta}\right\}-P(A)
$$


Where, $\mathrm{S}(\mathrm{w} ; \mathrm{A})$ and $\mathrm{P}(\mathrm{A})$ are the sales price and the dealer's purchase price repetitively. Where, $\tau$ is the age restoration, $c$ and $\bar{c}$ are the cost of improvement and expected cost of repair respectively and $\psi, \xi$ are the parameters of cost functions for upgrade action. $\lambda$ and $\beta$ are the Weibull parameters.

The optimal $\tau^{*}\left(0<\tau^{*}<\bar{\tau}\right)$ can be obtained by the usual first order condition (if it is an interior point of the admissible region) and if not, $\tau^{*}$ is either zero (implying no reliability improvement) or $=\bar{\tau}$ (implying maximum reliability improvement).

Problem 2: The sale price depends on the warranty terms. Upgrade (improvement) provides an opportunity to offer better warranty terms and this impacts on the profit. As a result, both upgrade (improvement) and warranty period are decision variables to be selected optimally to maximise the expected profit.

Here, the expected profit is given by

$$
J(w ; \theta ; A)=S(w ; A)-c \theta^{\psi} A^{\xi}-\bar{c} \lambda^{\beta}\left\lfloor(1-\theta)\left\{(A+w)^{\beta}-A^{\beta}\right\}+\theta w^{\beta}\right\rfloor-P(A)
$$

Where, $\theta$ is degree or level of improvement with $\theta=0$ means no upgrade and $\theta=1$ means repair quality as good as new and $\bar{c}$ is the expected cost of repair.

Chattopadhyay (2002) discussed parameter estimation for warranty cost associated with the sale of second-hand products. The claims (at the system level) for 1335 second-hand cars were obtained from an Australian insurance company, which acts as an underwriter for second hand car dealers. 558 warranty claim data were used for the analysis of expected warranty costs. The maximum likelihood estimates (for more details see Crowder et al [1991, pp 164-166]) were used for parameter estimation.

\subsection{Service Contracts}

For expensive and complex equipment (e.g., a power generation turbine), the maintenance service provider of the equipment needs to have expertise and specialised maintenance facilities to carry out appropriate maintenance. In many cases, owners find it economical to contract out the maintenance to an external agent (Ashgarizadeh and Murthy 2000). The external agent could be the manufacturer or an independent third party. Blischke and Murthy (2000) proposed a service contract with a scope for negotiation on coverage.

In the recent years, the concept of the service contract has received significant attention among the practitioners. But unfortunately only a few research work have so far been conducted on service contract. Murthy and Yeung (1995) proposed two models for service contract. They considered it in a demand-supply framework, where the user generates demand for maintenance service and the service provider acts as the supplier of service. In Model one, the service agent provides an immediate replacement on demand if the system fails before it reaches an age $T_{i}$. This could result in high inventory holding as the agent needs to hold spares as inventory. One way of reducing this cost is to order a spare at time $T_{0}\left(0<T_{0}<T_{i}\right)$ after a maintenance action is executed. The inventory cost decreases as $T_{0}$ increases. In Model two, the service agent is not in a position to provide an immediate replacement on demand. The agent compensates the user for the loss of revenue till the failed system is replaced.

Murthy and Ashgarizadeh (1995) developed a game theoretic model for service contract to characterise the optimal strategies for a single customer and a single agent. They considered exponential distribution for failure and repair times. Here, the service agent has two options: (i) to rectify all failures over the life of the equipment for a fixed price $(P)$ along with a penalty if the repair is not completed within the specified 
time, and (ii) to rectify each failure at a fixed price $\left(C_{s}\right)$ without penalty. The customer chooses the optimal decision to maximise its utility. Ashgarizadeh and Murthy (2000) extended this to develop a stochastic model for service contract to examine the optimal strategies for customers as well as the agent in a game theoretic setting. The many of the models discussed in this section considered a number of assumptions such as constant failure rate, replacement only with new items (if replacement is the only option), a constant repair cost and identical customers with risk neutral attitude. Therefore, these conditions could be relaxed to develop strategies for situations close to real life.

\subsection{Lifetime Warranties}

Lifetime warranty is becoming more and more important due to its application to longer life assets and enhanced customer demand on service from a product instead of procurement of products. As a result, in recent times, manufacturers of large number of consumer durable products have started offering lifetime warranties.

By lifetime warranty, it means the manufacturer/dealer's commitment to provide free or cost sharing maintenance service such as repair or replacement of the sold product in case of failure due to design or manufacturing defects throughout the useful life of the product or the buyer's ownership period of the product. The useful lifetime is defined as the lifetime of the product in the market and is assumed to be terminated in some finite, random time horizon. Outdated technology is not covered by lifetime warranty. Termination of such warranty may arise from the technological obsolescence, design modifications, change of component, or failure of a critical part that is not under such warranty coverage or even with the change of the ownership (Rahman and Chattopadhyay, 2004). Therefore, the useful life of the product under this type of warranty policy could be:

Technical life/ Physical life - the period over which the product might be expected to last physically, to when replacement or major rehabilitation is physically required.

Technological life - the period until technological obsolescence dictating replacement due to the development of a technologically superior alternative

Commercial life/ Economic life - - the period over which the need for the product exists, the period until economic obsolescence dictates replacement with a lower cost alternative.

Ownership life/ Social and legal life - the period until human desire or legal requirement dictates replacement or change of ownership occurs.

Despite its higher popularity and industrial potentiality, the area of lifetime warranty policy has received only a limited attention from academic researchers so far. Wells (1987) first proposed a computationally tractable expression for the total expected discounted future cost for a lifetime warranty policy. Wells also proposed to use phase type distribution to model system which evolve through stages during their lifetimes as these distributions are dense in the class of life distribution. He cited an example by using the matrix Laplace transformation to compute the total expected discounted lifetime warranty. According to his model, lifetime of the product assumed to be terminated at random time $T$. $T$ is a random variable of phase type with representation $(\theta, A)$ with $\underline{\theta} \underline{1}=1$ where $\underline{1}$ is a column vector of 1 's.

The total expected discounted warranty $\operatorname{cost} E(C)$ is given by

$E(C)=\sum_{i=1}^{\infty} E\left(C_{i}\right)$

where, $E\left(C_{i}\right)$ is the expected discounted warranty cost for $i$ th failure and is given by 
$E\left(C_{i}\right)=\int_{0}^{\infty} \int_{0}^{\infty} C_{i} k(w, z) d w d z$

where, $C_{i}$ is the discounted cost incurred during the $i$ th downtime and $k(w, z)$ is the joint distribution of $W_{i}$ ( the time that the $i$ th downtime begins) and $Z_{i}$ ( the observed length of $i$ th downtime) and $\mathrm{E}\left(\mathrm{C}_{\mathrm{i}}\right)$ is given by

$E(C)=\underline{\theta}\left[h_{0}+(h / \gamma)\left(I-A B^{-1}\right)\left(I-G_{B}\right)\right] F_{B}\left(F_{B} G_{B}\right)^{i-1} \underline{1}$

Where, $h_{0}$ and $h$ are the fixed and variable cost for each repair and $\gamma$ represents the discount rate. $F_{B}$ and $G_{B}$ are the matrix Laplace transformation of $f$ and $g$ respectably, where, $f($.) and $g($.$) are the density function corresponding to common distribution$ functions $F($.$) and G($.$) for failure and accumulated down times respectably. where B$ $=A-\gamma I$.

Finally the expected total warranty cost is given by

$E(C)=h_{0} \underline{\theta} F_{B}\left(1-F_{B} G_{B}\right)^{-1} \underline{1}+\left(\frac{h}{\gamma}\right) \underline{\theta}\left(I-A B^{-1}\right)\left(1-G_{B}\right) F_{B}\left(1-F_{B} G_{B}\right)^{-1} \underline{1}$

\section{Summary}

In this paper a review of long-term warranty policies for new and second-hand products is carried out. Important mathematical models for warranty cost analysis are covered. In the recent years, long-term warranty policies have attracted significant attention among practitioners. However, the published papers on long-term warranty policies and cost models are limited. It is observed that there is a recent shift of demand from product to the service of the product. In the future, companies might purchase total flying-hours instead of airplanes or welding or painting robot-hours instead of robots. This would result in greater importance to research on the long-term warranty policies, service contracts and development of real time complex cost sharing models in the near future. This paper provided a scope for future work working on these areas. Other areas for future research would be warranty terms for underwriting by insurance companies, application of preventive maintenance policies during warranty period, major overhauls, buy-back/ trade ins and replacement strategies during long-term warranty periods. There is huge scope for reducing costs and risks associated with these policies to Manufacturer/ dealer and consumer. Authors are currently working in some of these areas and results would be published in the future.

\section{References}

Amato, H. N., Anderson, E. E. (1976), Determination of warranty reserves: an extension, Management Science 22, 1391-1394.

Ashgarizadeh, E., Murthy, D. N. P. (2000), service contract: a stochastic model, Mathematical and Computer Modelling 31, 11-20.

Balachandran, K. R., Maschmeyer, R. A., Livingstone, J. L. (1981), Product warranty period: a markovian approach to estimate and analysis of repair and replacement costs, The Accounting Review 4: 59-76.

Bhat, B. R. (1969), Used item replacement policy, Journal of Applied Probability, 6, 309-318.

Blischke, W. R., Murthy, D. N. P. (1992), Product warranty management-I: taxonomy for warranty policies, European Journal of Operational Research, 62 127-148.

Blischke, W. R., Murthy, D. N. P. (1994), Warranty Cost Analysis, Marcel Dekker, Inc., New York.

Blischke, W. R., Murthy, D. N. P. (1996), Product Warranty Handbook, Marcel Dekker, Inc., New York. 
Blischke, W. R., Murthy, D. N. P. (2000), Reliability Modelling, Prediction and Optimisation, John Willey \& sons, Inc. New York.

Blischke, W. R. Scheur., E. M (1975), Calculation of the costs of warranty policies as a function of estimated life distributions, Naval Research Logistics Quarterly 22, 681-696.

Chattopadhyay, G.( 1999), Modelling and Analysis of Warranty Costs for Second-Hand Products, Published Ph.D. Thesis, The University of Queensland, Brisbane, Australia,.

Chattopadhyay, G., Murthy, D. N. P. (1996), Modelling warranties for second-hand products, Proceedings of second Australia Japan workshop on stochastic models in engineering, technology and management, Gold Coast, Australia, July 1996, 91-99.

Chattopadhyay, G., Murthy, D. N. P. (2000), Warranty cost analysis for second-hand products, Journal of Mathematical and Computer Modelling 31, 81-88.

Chattopadhyay, G., Murthy, D. N. P. (2001), Cost Sharing warranty policies for second-hand products, International Transactions in Operational Research 8.1, 47-60

Chattopadhyay, G. (2002), Analysis of warranty claims data for estimation of parameter for warranty cost models, 3rd Asia Pacific Conference on System Integration and Maintenance, Cairns, 2527 Sept 2002

Chattopadhyay, G., Murthy, D. N. P. (2004), Optimal reliability improvement for used items sold with warranty, International Journal of Reliability and Applications 5.2: 47-57.

Chukova, H., Arnold, R., Wang, D. Q. (2004), Warranty analysis: an approach to modelling imperfect repair. International Journal of Production Economics 89, 57-68.

Crowder, M. J., Kimber, A. C., Smith, R. L., Sweeting, T. J. (1991), Statistical Analysis of Reliability Data, Chapman \& Hall, London.

Dagpunar, J. S., Jack. N. (1994), Preventive maintenance strategies for equipment under warranty, Microelectronics Reliability 34(6), 1089-1093.

Davis, D. J. (1952), An analysis of some failure data, Journal of American statistical Association, 47, 113-150.

Djamaludin, I. A., Murthy, D. N. P. and Blischke, W. R. (1996), An annotated bibliography on warranties, in Product Warranty Handbook, W. R. Blischke and D. N. P. Murthy (eds), Marcel Dekker, New York, 1996.

Genesove, D. (1993), Adverse selection in the wholesale used car market, Journal of Political Economy, 101, 644-665.

Heschel, M. S. (1971), How much is a guarantee worth? Industrial Engineering 3, 14-15.

Hollis, A. (1999). Extended warranties, adverse selection and after markets, The Journal of Risk and Insurance, 66(3), 321-343.

Iskander, B. P., Murthy, D. N. P., Jack, N. (2005). A new repair-replacement strategy for items sold with a two-dimensional warranty, Computers and Operations Research, 32(3), 669-682.

Jack, N., Dagpunar, J. S. (1994). An Optimal Imperfect Maintenance Policy over Warranty Period, Microelectronics Reliability 34(3), 529-534.

Kaplan, E. L., Meier, P. (1958), Non Parametric Estimation from Incomplete Sample, Journal of American Statistical Association 53, 457-481

Karmarkar, U. S. (1978), Future Costs of Service Contracts for Consumer Durable Goods, AIEE Transactions 10, 380-387.

Kijima, M., Morimura, H., Sujuki, Y. (1988), Periodical replacement problem without assuming minimal repair, European Journal of Operational Research 37, 194-203

Kijima, M. (1989), Some results for repairable systems with general repair, Journal of Applied Probability 26, 89-102

Kumar, U. D., Chattopadhyay, G. (2004), Mathematical models for analysis of extended warranty. The Fifth Asia- Pacific Industrial Engineering And Management Systems Conference, p249, Gold Coast, Australia, 12-15 December, 2004.

Lowerre, J. M. (1968), On warranties, Journal of Industrial Engineering 19, 359-360.

Lutz, N., Padmabhaban, V. (1998), Warranties, extended warranties and product quality, International Journal of Industrial Organization 16, 463-493.

Malik, M. A. K. (1979), Reliable preventive maintenance policy, AIIE Transactions, 11, 221-228

Menke, W. W. (1962), Determination of warranty reserves, Management Science 15, 542-549.

Mitra, A., Patnakar, J. G. (1997), Market Share and Warranty Cost for Renewable Warranty Programs, International Journal of Production Economics 50,155-168.

Murthy, D. N. P. and Blischke, W. R. (1992a), Product warranty and management-II: An integrated framework for study, European Journal of Operational Research, 62, 261-281.

Murthy, D. N. P. and Blischke, W. R. (1992b), Product warranty and management-III: A review of mathematical models, European Journal of Operational Research 63, 1-34. 
Murthy D. N. P., Yeung, (1995) Modelling and analysis of service contracts, Mathematical and Computer Modelling 22(10-12), 219-225.

Murthy, D. N. P., Ashgarizadeh, E., (1995), Modelling service contracts. Presented at the INFORMS Meeting in New Orleans.

Murthy, D.N.P. and Chattopadhyay, G.N. (1999), Warranties for second-hand products, Proceedings of the Ninth International Conference of Flexible Automation and Intelligent Manufacturing (FAIM), Tilburg, Netherlands, June 1999, 1145-1159.

Murthy, D.N.P.; Djamaludin, I (2002), New product warranty: A literature review", International Journal of Production Economics 79(3), 231-260.

Murthy, D. N. P., Nguyen, D.G. (1985a), Study of two component system with failure interaction, Naval Research Logistics Quarterly, 239-247.

Murthy, D. N. P., Nguyen, D.G (1985b), Study of multi component system with failure interaction, European Journal of Operational Research 21, 330-338.

Murthy, D. N. P., Nguyen, D.G (1988), An optimal repair cost limit policy for servicing warranty, Mathematical and Computer Modelling 11, 595-599.

Murthy, D. N. P., Jack, N. (2003), Warranty and maintenance, in Hoang Pham edit.: Handbook of Reliability Engineering, 305-314.

Nakagawa, T. (1979), Optimum replacement policies for used unit, Journal of Operations Research, 22(4), 338-346.

Padmanabhan, V., Rao, R.C. (1993), Warranty policies and extended service contract: theory and an application to automobiles, Marketing Science 12, 230-247.

Padmanabhan, V. (1995), Usage heterogeneity and extended service contracts, Journal of Economics and Management Strategy, 12, 33-54

Rahman, A., Chattopadhyay, G.N. (2004), Lifetime warranty policies: complexities in modelling and industrial application, Proceedings Of The Fifth Asia- Pacific Industrial Engineering And Management Systems Conference, p249, Gold Coast, Australia, 12-15 December, 2004.

Rinsaka, K., Sandoh, H., (2001), A study on extension contract of warranty period, Transaction of the Institute of Electronics, Information and Communication Engineers 84, 528-542.

Ross, S.M., (1970), Applied Probability Models with Optimisation Application, Holden-Day Inc., San Francisco, CA, USA.

Wells, C. E. (1985), Determining the future costs of lifetime warranty, IIE Transactions 19(2), 178181.

Wogalter M.S, Vigilante W.J, and Baneth, R.C. (1998), Availability of operator manuals for used consumer products, Applied Ergonomics 29(3), 193-200.

Yeh, L., Peggo, K.W.L. (2001), An extended warranty policy with options open to consumers, European Journal of Operational Research 131, 514-529.

Mr Anisur Rahman is a PhD Research Scholar in the School of Engineering System, Queensland University of Technology (QUT), Brisbane, Australia since 2003. He obtained a Master by Research degree on modelling reliability and maintenance plan for infrastructure component from QUT, Australia in 2003. He obtained MSc Engineering in Engineering Management from QUT in 1999. His research area includes mathematical modelling, maintenance policies and cost analysis in maintenance, reliability and warranty. He has published 10 articles in international Journals and conference proceedings.

Dr. Gopinath Chattopadhyay is Senior Lecturer and Co-ordinator of Master of Engineering Management Program in the School of Engineering System, Queensland University of Technology, Australia. Dr. Chattopadhyay obtained his B. Eng from India during the year 1979. After working for 13 years in Indian manufacturing industries, he joined the postgraduate program of University of Queensland, Brisbane, Australia and obtained a PhD degree in field of Operations Management during 1999. $\mathrm{He}$ is President of Australian Society of Operations Research (Qld Branch) and Executive Committee Member of Maintenance Engineering Society of Australia. $\mathrm{He}$ is Secretary of the Asset Management and Maintenance Research Program at 
Queensland University of Technology. He is active in research projects under Centre of Integrated Engineering Asset Management and Centre of Railway Technologies research programs. His research interests are stochastic modelling in the area of product failure and degradation, reliability and maintenance cost analysis, Life Cycle Costing, Risk analysis, Warranty cost modelling and cost-benefit analysis of maintenance decisions for rail tracks. He is also member of the editorial boards and reviewer for many international journals. He has published more than 70 papers in International Journals and Conference proceedings. 